Sodium dinitro-o-cresylate caused a considerable reduction in effective perithecial development, and this was reflected in a low rate of discharge of ascospores.

Perithecia were plentiful in the leaves sprayed with sodium pentachlorophenate and were more advanced in maturity than those in the unsprayed leaves, ascospore discharge reaching peak intensity in mid-October. The rate of ascospore discharge was greater than from the leaves sprayed with sodium dinitro-o-cresylate but much less than that from the unsprayed leaves.

Further investigations have been undertaken this autumn (March-May) to determine the minimum concentration of phenyl mercuric chloride for eradication of Venturia inaequalis from infected apple leaves, and to test the possibility of eradicating apple scab from heavily infected isolated orchards using phenyl mercuric ehloride at high concentration immediately after the completion of harvesting. It is hoped that this eradication measure will also eliminate the fungus from infected bud-scales, a source of inoculum demonstrated by Cass Smith et al..$^{5}$ to be important in the disease cycle.

Full details of the techniques employed and results obtained in these investigations will be published elsewhere.

I wish to thank the field horticulturists of the N.S.W. Department of Agriculture who are assisting with these investigations, and Mr. E. C. Whittaker, fruit officer at Orange, in particular, whose cooperation in applying the sprays and forwarding sub-samples of leaves made possible the initial investigation.

Biological Branch,

K. E. Hutton

Department of Agriculture,

Sydney. July 21.

1 Keitt, G. W., and Palmiter, D. H., Abs. in Phytopathology, 27, 133 (1937)

2 Fitzgibbon. M., Fruitgrower, 155, 2719,141 (1948)

${ }^{3}$ Marsh, R. W., Rep. Agric. Hort. Res. Sta., 153 (Bristol, 1948).

- Byrde, R. J. W., Crowdy, S. H., and Roach, F. A., Ann. App. Biol., 39,681 (1952).

${ }^{5}$ Cass Smith, W. P., Harvey. H. L., and Goss, Olga, J. Dep. Aqric. Western Australia, 25 (Series 2), 129 (1948).

\section{Concentration of Potato Root Diffusate by Vacuum Distillation}

Ротато root diffusate, which is the liquid obtained by leaching growing potatoes with water, has long been known ${ }^{1}$ to contain an active factor which causes the larvæ to emerge from eggs contained within cysts of the potato root eelworm, Heterodera rostochiensis. Since the War, considerable research has been carried out in an attempt to ascertain the chemical constitution of the active factor ${ }^{2}$. At normal room temperature potato root diffusate is extremely unstable; hence the diffusate is stored in refrigerators, where it remains relatively stable for a considerable time.

Some method of concentrating the diffusate was imperative because it was becoming increasingly difficult to store bulk quantities of diffusate in refrigerators. The convenience of storage was the main reason for concentrating the diffusates, but other fectors are also of importance.

Dilutions of the concentrate could be used for a large number of assays at the same time, hence ensuring that each experiment received the same hatching stimulus and thus removing one difficulty normally encountered in eelworm assay. Moreover, the gradual decomposition of a sample of root diffusate can be corrected by concentration and subsequent redilution. There is no reason for supposing that concentrated root diffusates differ from ordinary samples in their rate of decomposition, so that while tests are being carried out on their relative stability, the concentrates are kept at $3-4^{\circ} \mathrm{C}$.

It was decided to prepare the concentrate by vacuum distillation at $5^{\circ} \mathrm{C}$. and a pressure of $1 \mathrm{~mm}$. mercury; the water which distilled was collected at $-20^{\circ} \mathrm{C}$., until the volume remaining in the still was between 1 and 4 per cent of the original. In some samples further concentration was effected by freeze drying. Afterwards, dilutions were prepared for biological assay so that concentrations lay on a logarithmic scale ${ }^{3}$.

Results showed that 90-95 per cent of the active principle remained undecomposed after vacuum distillation when comparing the diluted concentrate against the original sample. A rather greater loss, of 30 per cent, occurred with the freeze-dried material.

For all samples investigated an optimum hatch was observed (Table 1), confirming the suggestion by Calam et al.2. For concentrations higher than that which produce the optimum hatch, fewer larvæ emerged from the cysts. Thus two widely spaced concentrations of the hatching stimulant produce similar hatches, and this introduces complications into the bioassay of this substance, for which no chemical assay is as yet available.

Table 1. Percentage Hatoh of Larva hrom Cyst

\begin{tabular}{|c|c|c|c|c|c|c|c|c|}
\hline & \multicolumn{8}{|c|}{ Dilution of root diffusate } \\
\hline Exp. & $\frac{1}{1}$ & $\frac{1}{4}$ & $\frac{1}{16}$ & $\frac{1}{64}$ & $\frac{1}{256}$ & $\frac{1}{1024}$ & $\frac{1}{4096}$ & $\begin{array}{c}\text { Original } \\
\text { sample }\end{array}$ \\
\hline$A$ & 20 & 33 & 40 & 38 & 18 & $12 \cdot 5$ & $7 \cdot 6$ & 44 \\
$B$ & 78 & 79 & 84 & 78 & 65 & 43 & 19 & 87 \\
$C$ & 4 & 33 & 62 & 29 & 17 & 16 & 7 & 41 \\
\hline
\end{tabular}

It is not yet certain whether the reduced hatch at higher concentrations is due to inhibition by soil nutrient salts or to the root diffusate factor itself. Recent experiments in which the potatoes, grown in silver sand, are leached with distilled water, suggest that the inhibition is associated with enhanced concentrations of the hatching factor.

Imperial College Field Station,

N. G. Hague Silwood Park,

Sunninghill, Berks. Aug. 5.

1 Triffitt. M. J., J. Helminth., 8 (1), 19 (1930).

${ }^{2}$ Calam, C. T., Raistrick, H., and Todd, A. R., Biochem. J., 45, 513 (1949).

${ }^{3}$ Fenwick, D. W., J. Helminth., 25, 37 (1951).

\section{Augmentation of Wool-growth by I-Thyroxine and Tri-iodo-thyronine in Sheep}

THE photoperiodic response giving increased woolgrowth in sheep ${ }^{2}$ having been demonstrated, we are now endeavouring to trace the mode and function of this response. One section of a series of experiments designed to cover this aspect involved the use of hormone-replacement therapy. This required the acceptance as a working hypothesis that the pituitary gland is stimulated by the photoperiodic treatment so as to increase the output of the various hormones known to be associated with it, resulting finally in an increased rate of wool-growth. The availability 